\title{
SOB O SIGNO DE SATURNO: TRAUMAS E MEMÓRIAS DA GUERRA COLONIAL
}

\author{
Prof. Dr. Robson Dutra \\ (Unigranrio)
}

\section{RESUMO}

A partir dos conceitos de trauma e de memória, este texto tem como objetivo pensar traços da identidade cultural portuguesa em confronto os da guineense apresentados no romance A Última tragédia, de Abdulai Sila (1995), evidenciando algumas estratégias discursivas nas narrativas acerca do colonialismo e da Guerra Colonial. Discorre também para sobre a resistência dos dominados associada à componente trágica a que o texto alude e a história registra, servindo de veículo de questionamento e avaliação do pós-colonial.

PALAVRAS-CHAVE: trauma, memória, testemunho.

\begin{abstract}
From the concepts of trauma and memory on, the objective of this text is to think on some aspect of Portuguese cultural identity in confrontation with Guinean ones presented on the novel A Última tragédia, (The last tragedy) by Abdulai Sila (1995), reinforcing some discoursive strategies on colonialism and Colonial War. It also focuses on resistency associated to the tragedy brought up by the novel and registered by history as a way of questioning and evaluating the post colonial.
\end{abstract}

KEYWORDS: trauma, memory, testimony. 
Essa lembrança que nos vem às vezes...

folha súbita

que tomba

abrindo na memória a flor silenciosa

de mil e uma pétalas concêntricas.

Mario Quintana

O trauma é um tipo de dano ocasionado por um evento drástico que pode decorrer de catástrofes artificiais ou naturais, agressões, acidentes individuais ou coletivos, atentados guerras, ou seja, de uma variada gama de experiências dolorosas que afetam o ser humano física e/ou psicológica. A susceptibilidade a ele pode variar individualmente, de modo que alguém pode sentir como traumático um evento que para outro não o é.

A literatura, com maior ênfase na contemporaneidade, tem exemplificado um sem número de transtornos que envolvem o ser humano causando-lhe dores incontornáveis e desencadeando, no dizer de Márcio Selligmann-Silva, "uma espécie de deslocamento entre mente e corpo, ou seja, uma vontade de abandonar o corpo" Ou seja, ao não suportar os efeitos dolorosos da tortura física, a psique também é abalada, o que faz com que "para a psicanálise, a experiência traumática não seja assimilada de modo completo, resultando na repetição constante, alucinatória, por parte da vítima, da cena de impacto" (SELIGMANN-SILVA, 2008, p. 51).

Outros exemplos concretos desses abalos, em perspectiva que também tateia o literário, são descritos por Eduardo Lourenço em O Labirinto da Saudade, obra em que efetua alguns procedimentos de desmontagem da autoimagem de Portugal através da enumeração de uma sucessão de traumas ocorridos no seio daquela nação. Despindo o país da roupagem dos discursos hegemônicos, Lourenço exibe-o diante do espelho de si próprio e da Europa, revelando o espaço conflitual entre aquilo que ele é e a imagem idealizada que foi construída ao longo dos séculos. Revela-se, então, uma clivagem e um duplo estado de espírito em que se sente o que ontologicamente é (ou seja, um país pequeno, com recursos escassos e economia cada vez mais debilitada, por exemplo) e o que imageticamente lhe é rememorado pela leitura da História hegemônica (como o sonho do Quinto Império, as conquistas ultramarinas e a ideia de Estado uno, entre outros). Com isso, o país ocupa uma posição não muito confortável de definir-se como o centro de um império colonial e, simultaneamente, como uma periferia da Europa, condição definida por Boaventura de Sousa Santos como "semiperiferia" (SANTOS, 1986, p. 59), dada a ambiguidade das imagens centrais e periféricas que aí se projetam.

Contrariando a concepção secular de predestinação que rege a nação, exacerbando o decadentismo dos séculos XVII a XX e o "miserabilismo cultural” decorrente (LOURENÇO, 1978, p. 19), Eduardo Lourenço associa a trajetória portuguesa a uma série de "traumatismos", isto é, a 
graves perturbações civilizacionais que lhe recalcaram a possibilidade de uma vivência integrada à normalização média da existência europeia e a oscilação constante entre as duas posições mencionadas acima. O primeiro deles se relaciona diretamente com o espírito aventureiro, santo, guerreiro, mártir e heroico que assinala o surgimento do Condado Portucalense. Diferentemente do futuro "espírito cavalheiresco", D. Afonso Henriques possui um "espírito de guerreiro" que adormece todos os valores exceto os derivados do jogo de forças estabelecido no campo de batalha. Por isso, assinala Lourenço,

o nosso surgimento como Estado foi do tipo traumático e desse traumatismo nunca na verdade nos levantamos até à plena assunção da maturidade histórica prometida pelos céus e pelos séculos a esse rebento incrivelmente frágil para ter podido aparecer, e misteriosamente forte para ousar subsistir (LOURENÇO, 1978, p. 20).

Associando o nascimento de Portugal a um perfil freudiano através de atos perpetrados pelo primeiro monarca, e também por $\mathrm{D}$. Tareja e Egas Moniz (LOURENÇO, 1978, p. 20-21), o autor o associa a algo da ordem do injustificável, do "incrível", "milagroso" e "providencial" (LOURENÇO, 1978, p. 21), descrevendo o país como "conjunção de um complexo de inferioridade e de superioridade" que cumpre "uma única função: a de esconder de nós mesmos a nossa autêntica situação de ser histórico em estado de intrínseca fragilidade" (LOURENÇO, 1978, p. 21). Assim, torna-se comum a ocorrência de outros traumas, como o Ultimatum inglês de 1890 e a melancolia daí decorrente que buscaram refúgio na salvação social prometida pela República, mas que foi igualmente derrotada pelo Estado Novo salazarista. Isso faz com que o autor conclua que "cada período de forçado dinamismo tem sido seguido sempre do que, em linguagem freudiana, se chamaria o regresso do recalcado" (LOURENÇO, 1978, p. 26).

Lourenço aponta uma série de eventos relevantes durante o século XX, cujo ponto comum é a contradição entre um passado glorioso e a "diminuída realidade presente" (LOURENÇO, 1978, p. 29) que conduzirá a nação à Guerra Colonial, último esforço na defesa de um sonho passado e sem qualquer expressão concreta presente senão no campo do imaginário ("Portugal uno do Minho ao Timor"). Este, segundo ele, é o terceiro "traumatismo profundo - análogo ao da perda da independência" e a "um repensamento em profundidade da totalidade da nossa imagem perante nós mesmos e no espelho do mundo" (LOURENÇO, 1978, p. 45), ou seja, ao trágico desmoronar do Império, em 1975, e os muitos mitos aí envolvidos.

Marca constante do Império que se prolonga pela República, a saudade, o luto e a melancolia assumem, sob o "signo de Saturno" proposto por Roberto Vecchi e que tomamos emprestado no título desse trabalho, um lugar de destaque na literatura, tornando-se veículo de elaboração e de recomposição "quase terapêutica de traumas e lutos conhecidos" ao estabe- 
lecerem estreita aliança com a escrita da história, na tentativa de recompor, ingênua e desencantadamente, "fraturas com a experiência e descontinuidades com o passado” (VECCHI, 2010, p. 60).

A literatura produzida sobre as causas e efeitos da Guerra Colonial cumpre, portanto, a função de purgar dores decorrentes da imagem de Portugal sobre si mesmo, isto é, dos fatos que colocam a nação em posição ambígua. Para além disso, os traumas evidenciados trazem à tona também a perspectiva dos países africanos, antigas colônias ultramarinhas, o modo como estes não só partilham dos muitos dramas advindos do colonialismo, como também buscam purgar seus malefícios.

Tendo em vista o grande número de textos produzidos sobre Angola, Moçambique e Cabo Verde, sobretudo, optamos por, nesse estudo, determo-nos sobre a produção da Guiné-Bissau, cuja literatura desponta tão somente após a derrocada do sistema colonial, elegendo como corpus literário o romance A Última tragédia, de Abdulai Sila.

Como portador de sentidos diversos que integram o "sistema de signos mutáveis", Sila opta pelo romance: forma inerente à modernidade, tal gênero, associado a um "ato de solidariedade histórica" (BARTHES, 1981, p. 243), permite a análise de algumas questões cruciais à Guiné-Bissau. Assim, como estratégia narrativa, tal autor elege um tempo ainda colonial, mais especificamente os anos 50, época anterior, portanto, não só à publicação deste romance, em 1995, mas também aos traumas da descolonização.

Integrante da "geração da utopia" guineense que "acreditou no Homem e na construção de um todo diferente” (AUGEL, 1998, p. 333), Sila lança mão de estratégias caras à produção metaficcional para recriar uma gama de eventos que se entrecruzam, resultando num todo que se tece, em A Última tragédia, através da narrativa de três histórias distintas protagonizadas por Ndani, o Régulo Bsum Nanki e o Professor, mas que conduzem a um mesmo fim.

A internalização do olhar do outro, sobretudo o do colonizador, levou a aberrações que Sila encena, como os diversos preceitos da "catequese" executada nas colônias portuguesas que, dentre outras coisas, apresentava o "Dia de Portugal" como data nacional também naquelas localidades, ignorando a história local, seus mitos, suas tradições, línguas e a diversidade étnica que compõe esse país. Colocando as colônias na incômoda posição de periferia em confronto com a centralidade de Lisboa, o discurso colonial perpetrou arbitrariedades, marcadamente, um grave deslocamento no sentimento de pertença e de identidade cultural, forjando a pretensa unidade do continente e do ultramar.

Todavia, ao operar uma mudança de olhar, uma vez que as protagonistas do romance são os nativos, Sila desloca o locus de enunciação, demarcando um contradiscurso que desestabiliza a disseminação do colonialismo. Este tempo, simultâneo ao processo de sistematização da litera- 
tura guineense, revela Abdulai Sila como pioneiro na prosa romanesca e na busca da autoconsciência nacional escamoteada, numa temporalidade bastante posterior às das demais nações africanas. Nesse sentido, vale salientar que diversos fatores ajudam a explicar o fato de que a produção literária do país se desse tardiamente, entre eles: a escassez de portugueses ao longo do período colonial na Guiné Bissau - cuja função principal foi a de entreposto de escravos -, a multiplicidade étnica que, obviamente, traz consigo diferenças linguísticas e culturais, além de questões de ordem socioeconômica e política.

Contudo, a obra de Abdulai Sila surge com vigor e intensidade tais que redime a escrita do passado, recuperando alguns traços da literatura que lhe antecede ao mesmo tempo que afirma a sua mundividência através do resgate das "memórias subterrâneas" e traumáticas do colonialismo. De sua escrita emergem marcas da oralidade que caracterizam a memória ancestral da Guiné presente em sua narrativa, a que se acrescem traços do amor à terra tematizado pelo escritor Carlos Semedo, algumas questões inerentes ao universo feminino em conflito com o colonizador, tal qual se lê nos contos de Domingas Samy, bem como as diversas passadas escritas por Odete Semedo. Todos esses elementos comparecem na obra de Sila como uma força fautora de transformações. Do mesmo modo, identificam-se tensões abordadas por Filinto de Barros, em Kikia Matcho, o desalento do combatente ao discorrer sobre os dilemas vivenciados pela Guiné-Bissau pós-independente e às voltas com outros dramas advindos da Revolução.

Desse modo, sua escrita mantém um olhar atento sobre o tempo e sua ação formadora, de modo que os diversos momentos da história pessoal de suas personagens servem como representação de outros tantos níveis de compreensão do mundo e de si mesmo. A dimensão histórica do tempo é interiorizada, e mais importante que o desenrolar da narrativa é o processo em que se revela o acaso que regula a vida, sobretudo quando confrontado com a rigidez de propósitos e certezas que norteiam suas personagens.

Assim, a narrativa de A Última tragédia se inicia com o relato acerca de Ndani, jovem de treze anos que deixa Biombo, sua aldeia natal, em busca das "facilidades" do meio urbano, após ouvir o vaticínio do adivinho de sua tabanca de que jamais seria feliz ali. Com isto, a narrativa espelha alguns dos estratagemas colonialistas, como o de oferecer ao indígena um estilo de vida que, no final, lhe seria inacessível, uma vez que a perversidade desse sistema visava à privação de seus desejos, de sua língua, de suas tradições (SILA, 2006, p. 24) e mesmo de seu nome (SILA, 2006, p. 31), num processo de redução e de "coisificação" do homem africano. Algumas dessas "comodidades" podem ser lidas na comparação feita pela personagem com o djambaku, ou seja, o curandeiro, numa tensão entre a vida urbana e a rural:

ele devia ver o que é dormir numa cama de molas e comparar a diferença com um colchão de palha com troncos no meio; ele devia saber o que é dormir num quarto sem 
mosquitos a chatear e com ventoinha a soprar fresco toda a noite e comparar isso com o martírio de dormir com galinha e cachorro ao lado e dabi no colchão; ele devia experimentar para depois explicar às mulheres dele a diferença entre sentar-se de manhã a uma mesa e tomar calmamente o mata-bicho e o acordar com o segundo galo e começar a pilar arroz, ainda por cima com filho às costas; ele devia ver como é que com um simples truque de torcer uma torneira, só com dois dedos, sem o menor esforço, se podia obter a quantidade de água que se quisesse e comparar depois esse esforço com a canseira das mulheres da tabanca de caminhar distâncias enormes com pote ou balde grande na cabeça; ele devia ver a quantidade de carne que o cão daquela casa comia todos os dias e comparar com a comida que os meninos tinham na tabanca [...]; ele devia ver tudo o que o homem branco tem e ver se encontrava uma forma de convencer o Yran a ajudar a encontrar coisas parecidas para o homem preto, em vez de estar só a anunciar desgraças e tragédias (SILA, 2006, p. 44).

Contudo, a jovem segue tão somente o destino de muitas que se empregavam como criadas em casas senhorias, ou seja, as que aprenderam a língua e os costumes portugueses, foram batizadas e catequizadas pela patroa - aqui ironicamente caracterizada pela enunciação através do desejo civilizatório e messiânico do colonialista que sempre superestimou o alcance de sua penetração cultural -, até, por fim, serem violadas sexualmente pelo patrão católico.

A segunda narrativa, a do régulo de Quinhamel, um soba africano que lança mão daquilo que o colonizador lhe tentou tirar: a imaginação criativa. Por isso, a personagem elege o ato de pensar como a faculdade primordial do homem e é por intermédio dela que faz frente ao administrador colonial que, apesar de seu papel secundário na trama, representa o braço repressor do colonialismo:

É preciso encontrar uma saída. Por isso e para isso ele tinha tomado uma decisão: tinha que pensar, pensar sempre. E para pensar duas cabeças valem mais que uma. Três mais que duas e assim por diante. Claro que tem que haver limite. Pôr toda gente a pensar todo o tempo não dá, não é preciso exagerar. Três pessoas a pensar já era suficiente. Até porque é preciso ter em conta que onde há muito preto, djumbai não pode faltar. Se ainda tiver alguém com mania de djidiu no meio, então é festa todos os dias, porque de conversa vai passar à cantiga, sem falta (SILA, 2006, p. 69).

Desse modo, o régulo de Quinhamel faz valer a premissa de Michelle Perrot de que "entender as proibições é também compreender a força das resistências e a maneira de contorná-las ou subvertê-las" (PERROT, 1988, p. 127), rompendo silêncios e caminhando, portanto, mais além na descrição efetiva do país, em marcha franca para a independência que se avizinhava. Como líder local, o régulo torna-se subsidiário da vontade do administrador 
colonial, tendo de se adequar aos seus desmandos, ao menos aparentemente, de modo a evitar maiores malefícios do que os já vivenciados.

O terceiro e último eixo narrativo traz à cena o professor da escola mandada construir pelo régulo em seu projeto de desabrochamento do homem africano e de seu pensamento crítico. Curiosamente, esta personagem não é nominada no romance, numa clara alegorização à liberdade de pensamento e de ação desejada pelo régulo, ora posta em prática. Ao não lhe conceder um nome, Sila amplia a capacidade de contestação para além da personagem, fazendo, assim, do livre pensar uma característica comum aos que com ele aprenderam, conviveram ou dele ouviram falar.

Prova cabal desta intenção é a referência à sua exemplaridade no romance Mistida (1997), ao enfocar, já em enunciação pós-colonial, as tensões ocorridas na busca da liberdade e o modo como o estudo conduz o homem ao autoconhecimento que o habilita a projetar-se para além de si na busca de seus ideais.

Assim, a personagem, educada pela Igreja católica e fruto da depauperada vocação "messiânica" do sistema colonial, rejeita dogmas tradicionais, identificando-se, guardadas as proporções, com o mito do "bom selvagem" de Rousseau. Sua aproximação paulatina com o povo e com a realidade, que a catequese tentou obliterar, contudo, fazem-na constatar o equívoco cometido em sua formação e, num processo penoso, redefinir seus conceitos. Suas atitudes, a partir daí, terão papel de relevância no combate aos desmandos coloniais, visto que são estes atos que conduzem a Guiné à Guerra de Libertação. Por isso, sua preponderância no romance reside no fato de este professor capacitar seus alunos aos novos tempos, mostrando-lhes as vantagens de se aliar o pensamento à ação, a fim de superarem os terríveis e pesados traumas da história.

Como fiandeiro das palavras, Abdulai Sila compõe com estas personagens um vistoso colar, idêntico ao que Mia Couto se refere na epígrafe de seu livro de contos $O$ Fio das missangas, em que a voz do poeta, como um fio de silêncio, costura o tempo. Por isso, as três protagonistas de $A$ Última tragédia fazem valer a semântica da diferença que aponta significativamente para o conceito de "nação imaginada" proposto por Benedict Anderson e a partir do qual suas trajetórias podem ser pensadas.

Portador de novos sentidos, A Última tragédia revela o plurilingüismo do romance, defendido por Bakhtin, e que se dá em diversos níveis, como por exemplo na incorporação do léxico guineense, ou seja, do crioulo, à escrita literária. Com isso, Sila transgride a "cultura oficial" metaforizada no discurso redutor do colonizador às línguas nacionais e à própria oralidade, posta, outra vez, em curso. De modo semelhante, as diversas modificações na sintaxe e, sobretudo, na ideologia com que a língua portuguesa é empregada, representa uma reação "calibanesca" que faz audível a voz dos "vencidos da história", fazendo com que, em vez de mera via de purgação de dramas, a literatura seja, efetivamente, veículo de con- 
testação e de afirmação individual e coletiva. Com isso, aproximando-se do que afirma Linda Hutcheon (1988, p. 86), é através dessa perspectiva que se percebe o momento em que o centro cede lugar às margens, revelando o modo como os discursos totalizantes se constroem e tornando visíveis as suas contradições inerentes.

Ao gravitar em torno do inacabado, Sila faz com que sua literatura dedique espaço à representação daquilo que presencia no cotidiano de seu país. Com isso despontam outras dicções que são semelhantemente entreouvidas não apenas em uma, mas nas múltiplas tragédias que o romance e a própria história enunciam. Ao dessacralizar o prisma hegemônico de nação portuguesa, através de procedimentos como a ironia e a paródia, Sila revela o lado tosco e obtuso de "brancos de segunda" que, em Portugal, também seriam vítimas de um esmagamento político, econômico e social.

Oscilando entre traumas pessoais e, sobretudo, coletivos, a obra também revela a tragédia que circunda o régulo de Quinhamel que, apesar de priorizar o pensamento e superar habilmente o colonizador e suas artimanhas, não encontra interlocutores entre os seus, morrendo, por isso, sem concluir o testamento, seu legado formal aos seus descendentes. Dadas as circunstâncias que a envolvem, o régulo não consegue transpor o imenso abismo que a tradição abriu diante de seus pés ao constatar que Ndani, a jovem vítima do estupro perpetrado pelo antigo patrão e sua derradeira esposa, não era mais virgem, fazendo-o sofrer a vergonha e a humilhação que lhe conduziram à mufunesa, ou seja, à má sorte que lhe abreviou os dias. Renova-se aí, então, o trauma da violação colonial que não apenas desvirginou a jovem, mas, de igual modo, estilhaçou a tradição.

Por fim, lê-se também nas entrelinhas de A Última tragédia a história de jovens que, diferentemente de Ndani - que soube prevalecer sobre o discurso senhorial - pereceram, vítimas da aculturação, "naquele mundo branco tão diferente" (SILA, 2006, p. 133), a que foram conduzidas, vivendo e revivendo fatalidades como a de se entregarem, por exemplo, a um homem sem amor, adentrando, consequentemente, o mundo da prostituição. Em caminho idêntico ao destas jovens está ainda a tragédia de Antoninho, o jovem esbelto que foi sufocado pelos desejos lúbricos de sua patroa portuguesa até sofrer na pele o furor desmedido de seu senhor.

De modo semelhante, o trágico se faz presente na constatação de que, evocando epígrafe com que Pepetela inicia o romance A Geração da utopia, isto é, "os ciclos são eternos", Abdulai Sila traz à cena personagens que se opuseram veementemente ao colonialismo, como Mbunh Lambá e Obem Ko. As funestas situações por eles vividas tornam a se repetir com o Professor, filho de Ko, que, ao reagir à violência contundente perpetrada pelo administrador, foi responsabilizado por sua morte acidental, sendo condenado, por isso, ao degredo na Ilha de São Tomé.

Traços trágicos sombreiam ainda a trajetória acidentada de Ndani, que, violentada pela ideologia catequista de Dona Linda, pelos desejos 
carnais do patrão e pela rejeição do marido, é ainda privada do amor do homem que realmente amou e lhe deu filhos. Sua tragédia está, sobretudo, na derradeira constatação: a de que a imagem do curandeiro se sobrepusera à do Professor, alegorizando, com isso, a inexorabilidade de seu destino ao reafirmar o trauma colonial.

Num processo de questionamento que conduz seus leitores ao pensamento e à reflexão, Sila conclui seu romance relativizando, através da oralidade, o que acaba de contar. Através deste procedimento, descola-se o tempo de enunciação de seu texto e, regressando ao presente pós-colonial em que escreve, reavalia e redimensiona os discursos equivocados e autocelebrantes que permeiam a contemporaneidade guineense.

Tateando uma última vez o trágico, Abdulai Sila redimensiona a catarse dele advinda, alertando que este tipo de purgação e exorcismo tem de ser coletivizado, de modo a não permitir que o período pós-independência também acabe por resultar numa outra tragédia.

Aproximando-se do fim dessa exposição, percebemos que, tanto para Portugal quanto para a Guiné-Bissau e as demais nações africanas, "narrar o trauma tem em primeiro lugar o sentido primário de desejo de renascer" (SELIGMANN-SILVA, 2008, p. 66), de fazer com que, pela palavra, o sujeito afetado retorne ao seu cotidiano a fim de reconstruir o que o trauma estilhaçou. Todavia, sabemos que a linguagem é incapaz de descrevê-lo totalmente, seja pela via oral ou pela escrita, visto que ela não apreende a totalidade das coisas. Soma-se a isso o fato de o trauma desencadear um silenciamento que faz com que o ser afetado não expresse por meio do testemunho a sua dor, a sua versão dos fatos. Por isso, a base do testemunho consiste em uma ambiguidade: por um lado, a necessidade de narrar o que foi vivido, e por outro, a percepção de que a linguagem é insuficiente para dar conta do que ocorreu. Em virtude disso, surge um paradoxo que reforça o duplo aspecto que o trauma comporta: "a impossibilidade e a necessidade de sua representação. Diante do traumático, um testemunho se assenta necessariamente sobre a experiência-limite de um narrador que perfurou a barreira entre a vida e a morte" (MALDONADO; CARDOSO, 2009 , p. 9). É devido à dificuldade de narrar o trauma que a imaginação adentra a narrativa testemunhal. Isso ocorre de três formas.

Na primeira delas, o trauma resulta, pela memória e pela imaginação, na narração. Por isso, o narrador narra, em primeira pessoa, o que presenciou. Seligmann-Silva, em Testemunho da Shoah e literatura, destaca a figura do superstes que "sobrevive" ao lager, ou seja, ao campo de concentração. Sendo assim, o supertes alegoriza o testemunho, tendo em vista que esta é uma forma de esquecer o momento traumático. Para o autor, "a imaginação é chamada como arma que deve vir em auxílio ao simbólico para enfrentar o buraco negro do real do trauma" (SELIGMANN-SILVA, 2008, p. 70). Uma vez que o narrador não consegue narrar integral e linearmente o que viveu, o que vem à tona são as lembranças traumáticas que fazem 
com que ele retorne, invariavelmente, ao momento do trauma. Logo, esse tipo de memória o reconduz ao sofrimento, sendo mais fácil para o supertes narrar a sua versão por meio da alegoria - ou mesmo narrar antes o que aconteceu com outras pessoas do que consigo mesmo, justamente porque esta é uma maneira de esquecer o seu trauma. Assim, ocorre o postulado de Paul Ricoeur de que "narrar um drama é esquecer o outro" (RICOEUR, 2000, p. 459).

A segunda se dá através da narrativa em terceira pessoa do singular. Ainda para Seligmann-Silva, o testis é aquele que não vivenciou o trauma que narra. Por isso, "a pessoa que pode melhor escrever sobre os campos de concentração é quem não esteve lá e lá entrou pelas portas da imaginação" (SELIGMANN-SILVA, 2008, p. 71). Mais que isso, pode falar da perversidade colonial que a narrativa de Abdulai Sila evoca. Apesar do esquecimento pós-traumático, a memória é acionada e, conjugada à imaginação, recria e testemunha os fatos.

Por fim, na terceira, o testemunho se realiza através da neutralização do ficcional. Nela, a literalização resulta da incapacidade de traduzir o vivido em imagens ou metáforas. Desta forma, é imprescindível o uso da imaginação no testemunho para a transmissão do que se quer dizer. Para Seligmann-Silva (2009) a fragmentação de certo modo também literaliza a psique cindida do traumatizado e a apresenta ao leitor sob a forma testemunhal. A incapacidade de incorporar continuamente imagens exatas também marca a memória dos traumatizados. Dessa maneira, o testemunho também é "uma tentativa de reunir os fragmentos do 'passado' (que não passa), dando um nexo e um contexto aos mesmos". Por isso, "o testemunho não é o literário - onde não existe a mentira, mas apenas a 'verdade estética”" (SELIGMANN-SILVA, 2005a, p. 92).

Seja na produção literária portuguesa, seja na africana, os traumas coletivos e individuais, uma vez registrados na memória tanto coletiva quanto individual, integram o passado sombrio do ser humano. Apesar do silenciamento que, inicialmente, caracteriza o sujeito, as lembranças armazenadas são gradualmente elaboradas a fim de que, pela palavra, o sujeito se liberte da zona nebulosa que caracteriza os traumas e dramas a que foi submetido, abrindo-se, então, a novas perspectivas.

\section{REFERÊNCIAS BIBLIOGRÁFICAS}

ANDERSON, Benedict. Nação e consciência nacional. São Paulo: Ática, 1989.

AUGEL, Moema Parente. A Nova literatura da Guiné-Bissau. Bissau: INEP, 1998.

BARTHES, Roland. Fragmentos de um discurso amoroso. Rio de Janeiro: Francisco Alves, 1981.

HUTCHEON, Linda. Poética do pós-modernismo. Rio de Janeiro: Imago, 1988. 
LOURENÇO, Eduardo. O Labirinto da Saudade. Lisboa: D. Quixote, 1978.

MALDONADO, Gabriela; CARDOSO, Marta Rezende. "O trauma psíquico e o paradoxo das narrativas impossíveis, mas necessárias”. In: Psicologia Clínica, Rio de Janeiro, v. 21, n. 1, p. 45-57, 2009.

PERROT, Michelle. Os Excluídos da história. Rio de Janeiro: Paz e Terra. 1988.

RICOEUR, Paul. História, Memória. Esquecimento. Campinas: EdUNICAMP, 2008.

SANTOS, Boaventura Sousa. Pela mão de Alice: o social e o político na pós-modernidade. Porto: Afrontamento, 1996.

SELIGMANN-SILVA, Márcio. Narrar o trauma - a questão dos testemunhos de catástrofes históricas. Psicologia clínica, Rio de Janeiro, v. 20, n. 1, p. 65-82, 2008.

. O local da diferença: Ensaios sobre memória, arte, literatura e tradução. São Paulo, Editora 34, 2005.

. Testemunho e a política da memória: o tempo depois das catástrofes. Projeto história. n. 30, p.31-78, 2005a.

. Testemunho da Shoah e literatura. Palestra proferida na X Jornada Interdisciplinar sobre o ensino da história do Holocausto. São Paulo, 2009 .

SILA, Abdulai. A Última tragédia. Rio de Janeiro: Pallas, 2006.

VECCHI, Roberto. Exceção atlântica. Pensar a literatura da guerra colonial. Porto: Afrontamento, 2010.

Recebido para publicação em 29/05/2013

Aprovado em 19/08/2013 